\title{
Ergonomía y factores humanos en la lucha contra el COVID-19
}

\author{
Ergonomics and human factors in the fight against COVID-19
}

\section{Sr. Editor:}

El Perú es uno de los países más afectados por la pandemia del Covid-19, hasta la fecha la cifra de contagios va en aumento (1), los cuales en un sistema de salud fragmentado y desorganizado como el nuestro es perjudicial. Por esta razón es necesario sumar esfuerzos y la ergonomía y factores humanos (EFH) puede contribuir significativamente a esta lucha; por ello, el presente documento pretende describir la importancia de la EFH en la lucha contra covid-19.

La ergonomía y factores humanos es una disciplina científica cuyo objetivo principal es investigar las interacciones de los humanos con los elementos de los sistemas con la finalidad de mejorar el bienestar de los usuarios así como optimizar el desempeño de los sistemas (2). El carácter proactivo de la EFH es la clave para la mejora de los sistemas evitando así accidentes, eventos adversos y complicaciones que puedan afectar directamente la seguridad de los pacientes (SP) y de los trabajadores de salud (TS)(3).

Este sistema de trabajo está conformado por los siguientes elementos: las tareas, la organización, el ambiente, la tecnología y en el centro interactuando con cada una de ellas, el humano. En el actual contexto de la pandemia por Covid-19 esta dinámica entre elementos se ve afectada especialmente por la agresividad del virus lo cual obliga al sistema a responder rápidamente a pesar de sus debilidades. Para enfrentar las debilidades del sistema usualmente los TS deben enfrentar las carencias con sus propios recursos adaptándose de manera reactiva a los sistemas poniendo en riesgo su propia vida (4). Por esta razón, es necesario que estos ajustes sean favorables y la EFH contribuye significativamente.
Actualmente, se están trabajando diferentes iniciativas tales como la construcción de ventiladores mecánicos, producción y compra de equipos de protección personal (EPP), entre otros $(5,6)$. Las altas cargas mentales de los TS así como la alta variabilidad de las tareas pueden incrementar la tasa de errores al interactuar con los ventiladores y dispositivos médicos. La poca interacción entre los TS y los diseñadores pueden generar una brecha de desinformación aumentando la posibilidad de fallas y errores, es ahí donde la EFH puede contribuir optimizando la usabilidad, y SP. Por esta razón los dispositivos médicos deben ser sencillos de aplicar y a pesar de existir probabilidad de error no deben causar daño al paciente (7).

En el Reino Unido se formuló una guía para el diseño de ventiladores para Covid tomando en cuenta la EFH, de tal forma que puedan ser operados eficientemente sin dañar a las personas (8). En una reciente investigación (actualmente en curso) realizada a TS en primera línea contra Covid-19 señalaron grandes niveles de discomfort y dificultades por el uso de diversos EPP (9). Por ejemplo, los protectores faciales se empañaban fácilmente limitando la visión, las mascarillas eran reajustadas continuamente debido al discomfort llevando a los TS a tener que tocarse el rostro continuamente para acomodarse lo cual debe ser evitado para reducir riesgo de contagio. Muchos EPP son diseñados especialmente para percentiles de poblaciones con grandes estaturas siendo las mujeres el grupo más afectado. El Perú al ser uno de los países con menores estaturas en el mundo (10) tiene menos probabilidades de adecuación al EPP, por ello la EFH podría orientar las compras basados en la antropometría que faciliten una óptima adecuación del EPP.

1. University of Nottingham. Nottingham, Inglaterra.

a. Terapeuta Ocupacional. Magister en Ergonomía. Doctorando en Ergonomía y Factores Humanos, Orcid : ORCID: https://orcid.org/0000-0001-7263-9215 


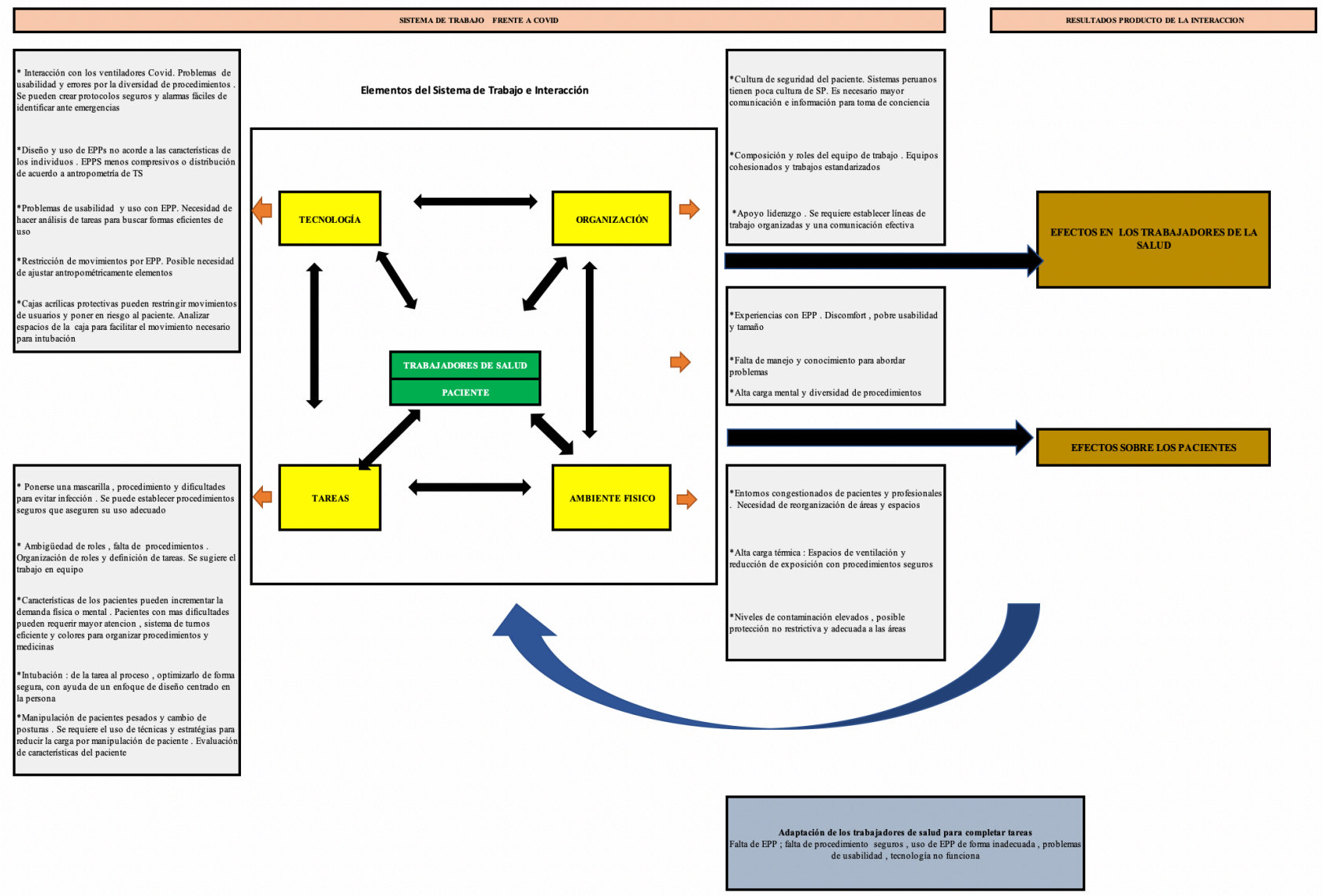

Figura 1. Ejemplos de problemas de Interacción de los elementos del sistema de Trabajo y oportunidades para la actuación de EFH

Con respecto al ambiente estos pueden tornarse muy calurosos especialmente cuando los TS usan el equipo completo resultando muy incómodo y restrictivo para trabajar. Estas condiciones descritas sumadas a las largas jornadas generan una alta carga de trabajo que pone en riesgo la SP y de los TS, por ello la EFH brinda recomendaciones para que se reduzca la carga física y mental de los TS a partir de la transformación del trabajo. Esta dinámica se ejemplifica en la figura 1. Por ello señor editor en estos tiempos de pandemia es necesario unir esfuerzos y los ergónomos somos pieza clave para optimizar el sistema sumando esfuerzos conjuntos para salvaguardar la SP y de los TS. Los ergónomos en el Perú, profesionales con especialización en EFH, participan activamente en las universidades y muchos de nosotros estamos agrupados en la Sociedad Peruana de Ergonomía (SOPERGO), sociedad científica con más de 15 años de fundada cuyos aportes han fomentado el desarrollo de la ergonomía en el país.

\section{Carlos Manuel Escobar-Galindo 1,a}

\section{Correspondencia:}

Human Factors Research Group

ITRC Building, Faculty of Engineering

The University of Nottingham

University Park

Nottingham

NG7 2RD

Tel: +51994391336

Correo electrónico:

manuel.escobar@nottingham.ac.uk

\section{REFERENCIAS BIBLIOGRÁFICAS}

1. Instituto Nacional de Salud. Centro Nacional de Epidemiología; Prevención y Control de Enfermedades. Total de casos positivos Covid en el Perú. Lima: Ministerio de Salud; 2020. Disponible en: https://covid19.minsa.gob.pe/sala_situacional.asp 03/06/2020

2. Dul J, Bruder R, Buckle P, et al. A strategy for human factors/ergonomics: developing the discipline and profession. Ergonomics. 2012; 55(4):377-95. 
3. Hignett S, Carayon P, Buckle P, Catchpole K. State of science: human factors and ergonomics in healthcare. Ergonomics. 2013; 56(10):1491-503.

4. Carayon P, Hundt AS, Karsh B, Gurses AP, Alvarado CJ, Smith M, et al. Work system design for patient safety: the SEIPS model. Qual Saf Health Care. 2006; 15(Suppl 1):i50-8.

5. Guzman I. Ingenieros PUCP diseñan ventiladores pulmonares para atender emergencias por coronavirus. Lima: Pontificia Universidad Católica del Perú; 2020. (Citado el 3 de junio de 2020) Disponible en: https:// puntoedu.pucp.edu.pe/noticias/ingenieros-pucpdisenan-ventiladores-pulmonares-para-atenderemergencias-por-coronavirus/

6. Universidad Nacional Mayor de San Marcos. COVID-19: Estudiante de posgrado crea equipos de protección personal mediante impresiones 3D. Lima: Universidad Nacional Mayor de San Marcos; 2020. (Citado el 03 de junio de 2020) Disponible en: http://www.unmsm.edu.pe/noticias/ver/COVID19-Estudiante-posgrado-equipos-proteccionpersonal-mediante-3D

7. Wiklund M, Weinger M. General Principles. En: Weinger M, Wiklund M, Gardner-Bonneau D. Human Factors in medical Device Design. Boca Raton Florida: CRC press; 2011.
8. Chartered Institute of Ergonomics and Human Factors. Human Factors in the Design and Operation of Ventilators for Covid-19. Londres: Chartered Institute of Ergonomics and Human Factors; 2020. (Citado el 23 de junio de 2020) Disponible en: www. ergonomics.org.uk

9. Chartered Institute of Ergonomics and Human Factors. CIEHF survey confirms serious PPE problems on the frontline. Londres: Chartered Institute of Ergonomics and Human Factors; 2020 (Citado el 3 de junio de 20202) Disponible en: https://www.ergonomics.org.uk/Public/Think/ CIEHF-survey-confirms-serious-PPE-problemson-the-frontine.aspx?fbclid=IwAR0rbMvPJ PkbM5Z9fTUseEhWuW1_ar9U0M8wRfm4Mb W96q-ZFWZSeaiREM

10. Franco E. (Editor). A century of trends in adult human height. eLife. 2016; 5:e13410. doi: 10.7554/eLife. 13410

Recibido: $15 / 06 / 2020$ 